\title{
Factorial Analysis on Individual Variability of Tacrolimus Extended- Release Formulation Pharmacokinetics in the Early Period after Renal Transplantation-Factors for AUTL/AUC Decrease
}

Yuki Nakamura ${ }^{1 *}$, Hironori Takeuchi², Hitoshi Iwamoto', Tatsunori Toraishi ${ }^{3}$, Osamu Konno ${ }^{1}$, Yu Kihara', Takayoshi Yokoyama', Toshihiko Hirano $^{4}$, Kiyoshi Okuyama ${ }^{3}$, Hiroaki Katayama ${ }^{2}$, Takashi Kawaguchi ${ }^{2}$, Sakae Nezaki ${ }^{1}$ and Shigeyuki Kawachi ${ }^{1}$

${ }^{1}$ Department of Digestive and Transplantation Surgery, Tokyo Medical University Hachioji Medical Center, Japan

${ }^{2}$ Department of Practical Pharmacy, Tokyo University of Pharmacy and Life Sciences, Japan

${ }^{3}$ Department of Pharmacy, Tokyo Medical University Hachioji Medical Center, Japan

${ }^{4}$ Department of Clinical Pharmacology, Tokyo University of Pharmacy and Life Sciences, Japan

\begin{abstract}
Background: We have often observed that the blood trough concentration $(\mathrm{Ct})$ of the once-daily, prolonged-release formulation of tacrolimus (Graceptor ${ }^{\circledR}$; GRC) becomes unstable, and it is difficult to adjust it in the early period after transplantation. Consequently, we compared the relationships between pharmacokinetic parameters and influencing factors in a group of GRC-treated patients compared with those in a group of Prograf ${ }^{\circledR}$ (PRG)-treated patients.

Methods: The study included 8 patients who were newly treated with GRC and 44 patients who were newly treated with PRG. We performed 24-hour therapeutic drug monitoring to compare the relationships between pharmacokinetic parameters, including the area under the curve (AUC), the ratio of the area under the trough level (AUTL)/AUC to indicate the relationships among AUCs, peak concentration $\left(C_{p}\right)$, and $C_{t}$. The $C_{p} / C_{t}$ values, and dose/body weight $(U C /$ [D/BW]) values reflected bioavailability and the influencing factors; number of days after transplantation and Dose/BW in the GRC-treated and PRG-treated patients.

Results: The $C_{p} / C_{t}$ values were higher and the AUTL/AUC and AUC corrected by dose/body weight (AUC/[D/BW]) values were lower with a low number of days after transplantation (particularly within 20 days) and a large dose than a high number of days after transplantation and a small dose in the GRC-treated patients. No such associations were observed in the PRG-treated patients.

Conclusion: Care is required when using GRC as there is a tendency for $\mathrm{C}_{\mathrm{p}}$ to increase owing to rapid absorption within 20 days after transplantation. Blood levels may be unstable and side effects may be more prevalent in some patients. Moreover, the utilization rate is low and the dose is high in such patients; therefore, unstable gastrointestinal function caused by a variety of factors may play a role in the early period after transplantation.
\end{abstract}

Keywords: Tacrolimus extended-release formulation; AUTL/AUC; Pharmacokinetics; Individual variability

Abbreviations: AUC: Area Under the Curve; AUTL: Area Under the Trough Level; BW: Body Weight; Cp: Peak Concentration; Ct: Trough Concentration; D: Dose; GRC: Graceptor ${ }^{\bullet}$ MMF: Mycofenolate Mofetil; PRG: Prograf ; TAC: Tacrolimus.

\section{Introduction}

The most common regimen following kidney transplantation involves treatment with one of four immunosuppressive agents (tacrolimus [TAC], mycofenolate mofetil [MMF], basiliximab, and corticosteroid) and has been shown to achieve excellent outcomes. The pharmacokinetics of Graceptor (GRC TAC QD) differ slightly from those of tacrolimus BID [Prograf; PRG] as a result of differences in the inactive ingredients included in the capsules. Some authors have previously reported the use of GRC in patients undergoing kidney transplantation. [1-4]. For example, after renal transplantation, recipients are switched from TAC-BID to an equivalent dose of TAC$\mathrm{ER}$, and the trough concentration $\left(\mathrm{C}_{\mathrm{t}}\right)$ of TAC became lower than that before switching. [5-9]. Moreover, we have often observed that the $\mathrm{Ct}$ of GRC becomes unstable over time, making it nearly impossible to titrate the dosage up, and it can be difficult to adjust the dosage in the early period after transplantation. Thus, the aim of the present study was to analyze pharmacokinetic parameters to determine the factors leading to unstable $\mathrm{Ct}$ in GRC-treated patients in early-phase renal transplantation and compare them to those for PRG-treated patients.

\section{Material and Methods}

The study included 8 patients who were newly treated with GRC and 44 patients who were newly treated with PRG. We performed 24-hour therapeutic drug monitoring to compare the relationships between pharmacokinetic parameters and influencing factors in the GRC-treated and PRG-treated patients. In the GRC-treated patients, GRC was administered once a day at $8 \mathrm{AM}$ after breakfast, and blood samples were collected at the following 9 time points: immediately before administration, and $1,2,3,4,6,12,18$, and 24 hours after administration. In the PRG-treated patients, equal doses of PRG were

*Corresponding author: Nakamura Y, Tokyo Medical University Hachioji Medical Center Postal address: 1163 Tatemachi, Hachioji-City, Tokyo 193-0998, Japan, Tel: +81-42-665-5611, extn. 7004; Fax: +81-42-665-1796; E-mail: yn70@tokyo-med.ac.jp

Received: December 15, 2015; Accepted: January 29, 2016; Published: January 31, 2016

Citation: Nakamura Y, Takeuchi H, Iwamoto H, Toraishi T, Konno O, et al. (2016) Factorial Analysis on Individual Variability of Tacrolimus Extended-Release Formulation Pharmacokinetics in the Early Period after Renal TransplantationFactors for AUTL/AUC Decrease. J Kidney 2: 112. doi:10.4172/2472-1220.1000112

Copyright: (c) 2016 Nakamura Y, et al. This is an open-access article distributed under the terms of the Creative Commons Attribution License, which permits unrestricted use, distribution, and reproduction in any medium, provided the original author and source are credited. 
Citation: Nakamura Y, Takeuchi H, Iwamoto H, Toraishi T, Konno O, et al. (2016) Factorial Analysis on Individual Variability of Tacrolimus ExtendedRelease Formulation Pharmacokinetics in the Early Period after Renal Transplantation-Factors for AUTL/AUC Decrease. J Kidney 2: 112. doi:10.4172/2472-1220.1000112

Page 2 of 5

administered at $8 \mathrm{AM}$ and $8 \mathrm{PM}$ after a meal, and blood samples were collected at the following 7 time points for both administrations: immediately before administration, and $1,2,3,4,6$, and 12 hours after administration. As there were morning-evening differences in the pharmacokinetic parameters among the PRG-treated patients, the parameters were calculated separately for the morning and evening administrations.

We analyzed the relationships among each of the pharmacokinetic parameters, including the ratio of the area under the trough level to the area under the curve (AUTL/AUC), representing the relative involvement of peak concentration $\left(\mathrm{C}_{\mathrm{p}}\right)$ and $\mathrm{C}_{\mathrm{t}}$ in the AUC $[10], \mathrm{C}_{\mathrm{p}} / \mathrm{C}_{\mathrm{t}}, \mathrm{AUC} /($ dose $[\mathrm{D}] /$ body weight $[\mathrm{BW}])$, representing the relative estimate of bioavailability corrected with dose per body weight, and the number of days after transplantation.

Statistical Analyses: Statistical values in the present study are expressed as Mean \pm SD for each group. Data were analyzed using a logistic regression analysis (JMP Version 8.0.2, SAS Institute Japan Ltd.). The coefficient of correlation was derived from the Fisher's $\mathrm{z}$ transformation. A value of $\mathrm{p}<0.05$ was considered statistically significant.

\section{Results}

The pharmacokinetic parameters among the GRC-treated and

\begin{tabular}{|c|c|c|c|}
\hline & \multirow{2}{*}{ GRC $(n=8)$} & \multicolumn{2}{|c|}{ PRG (n=44) } \\
\hline & & Morning & Evening \\
\hline Age (years) & $51.6 \pm 15.9$ & \multicolumn{2}{|c|}{$45.3 \pm 12.6$} \\
\hline Male/female & $5 / 3$ & \multicolumn{2}{|c|}{$30 / 14$} \\
\hline Dose (mg/day) & $6.4 \pm 5.2$ & \multicolumn{2}{|c|}{$9.2 \pm 4.8$} \\
\hline Weight (kg) & $53.4 \pm 9.1$ & \multicolumn{2}{|c|}{$53.0 \pm 9.6$} \\
\hline Number of days elapsed after transplantation & $26.4 \pm 15.2$ & \multicolumn{2}{|c|}{$33.8 \pm 21.2$} \\
\hline D/BW (mg/kg/day) & $0.11 \pm 0.09$ & \multicolumn{2}{|c|}{$0.18 \pm 0.09$} \\
\hline $\mathrm{C}_{\mathrm{p}} /(\mathrm{D} / \mathrm{BW})(\mathrm{ng} / \mathrm{mL}) /(\mathrm{mg} / \mathrm{kg})$ & $293.4 \pm 139.3$ & $292.1 \pm 159.9$ & $252.3 \pm 141.9$ \\
\hline $\mathrm{C}_{\mathrm{t}} /(\mathrm{D} / \mathrm{BW})(\mathrm{ng} / \mathrm{mL}) /(\mathrm{mg} / \mathrm{kg})$ & $122.9 \pm 99.9$ & $160.3 \pm 110.0$ & $172.8 \pm 121.4$ \\
\hline AUTL/AUC & $0.68 \pm 0.21$ & $0.74 \pm 0.11$ & $0.82 \pm 0.12^{*}$ \\
\hline $\mathrm{C}_{\mathrm{p}} / \mathrm{C}_{\mathrm{t}}$ & $3.17 \pm 1.45$ & $1.99 \pm 0.58^{*}$ & $1.60 \pm 0.48^{\star}$ \\
\hline $\mathrm{AUC} /(\mathrm{D} / \mathrm{BW})(\mathrm{ng} / \mathrm{mL} \cdot \mathrm{h}) /(\mathrm{mg} / \mathrm{kg})$ & $3910 \pm 2295$ & \multicolumn{2}{|c|}{$2424 \pm 1480^{*}$} \\
\hline
\end{tabular}

Table 1: Comparison of pharmacokinetic parameters between the GRC-treated patients and the PRG-treated patients. 
Citation: Nakamura Y, Takeuchi H, Iwamoto H, Toraishi T, Konno O, et al. (2016) Factorial Analysis on Individual Variability of Tacrolimus ExtendedRelease Formulation Pharmacokinetics in the Early Period after Renal Transplantation-Factors for AUTL/AUC Decrease. J Kidney 2: 112. doi:10.4172/2472-1220.1000112

Page 3 of 5

PRG-treated patients are presented in Table 1. The AUTL/AUC values were significantly lower among the GRC-treated patients than among the PRG-treated patients (evening administration). Additionally, the $\mathrm{C}_{\mathrm{p}} / \mathrm{C}_{\mathrm{t}}$ values were significantly higher among the GRC-treated patients than among the PRG-treated patients (both morning and evening administration). Moreover, the AUC/(D/BW) values were significantly higher among the GRC-treated patients than among the PRG-treated patients.

With regard to the relationships among each parameter and the number of days after transplantation, the AUTL/AUC and AUC/(D/ $\mathrm{BW}$ ) values were lower and the $\mathrm{C}_{\mathrm{p}} / \mathrm{C}_{\mathrm{t}}$ values were higher within 20 days post-transplantation than after 20 days post-transplantation in the GRC-treated patients (Figure 1A-1C). With regard to the relationships among each parameter and the D/BW, the AUTL/ AUC and $\mathrm{AUC} /(\mathrm{D} / \mathrm{BW})$ values were lower and the $\mathrm{C}_{\mathrm{p}} / \mathrm{C}_{\mathrm{t}}$ values were higher with high $\mathrm{D} / \mathrm{BW}$ values than with low $\mathrm{D} / \mathrm{BW}$ values in the GRC-treated patients (Figure 2A-2C). No such associations were observed in PRG-treated patients. The observed relationship between the $\mathrm{D} / \mathrm{BW}$ and $\mathrm{AUC} /(\mathrm{D} / \mathrm{BW})$ values resulted from the fact that we raised the $\mathrm{D} / \mathrm{BW}$ values in patients with low $\mathrm{AUC} /(\mathrm{D} / \mathrm{BW})$ values because the blood levels of the drug did not rise. Negative correlations (correlation coefficient values: $r>0.6$ ) were observed for not only GRC administration, but also morning and evening administration of PRG. Furthermore, the AUTL/AUC values were lower and the $C_{p} / C_{t}$ values were higher with low $A U C /(D / B W)$ values than with high $\mathrm{AUC} /(\mathrm{D} / \mathrm{BW})$ values in the GRC-treated patients (Figure $3 \mathrm{~A}$ and $3 \mathrm{~B}$ ).

\section{Discussion}

The findings of the present study indicate that in the GRC-treated patients, the gastrointestinal function reduced within 20 days posttransplantation owing to various postoperative influences and the bioavailability (AUC/[D/BW]) easily decreased; thus, high doses (D/ BW) were administered in some patients, which resulted in unstable blood levels. In addition, the dose of GRC was twice as much as that of PRG, which resulted in a larger amount of GRC than PRG being present in the gastrointestinal tract. Consequently, when the extended drug release was changed by some factors and the absorption rate increased, the abrupt absorption of a large amount of GRC present in the gastrointestinal tract occurred, which caused more frequent increases in the $\mathrm{C}_{\mathrm{p}} / \mathrm{C}_{\mathrm{t}}$ values and decreases in the AUTL/AUC values compared to those with PRG [5] (Figure 4).

In such patients, controlling blood levels is difficult, and side effects can easily occur owing to increased $\mathrm{C}_{\mathrm{p}}$. Furthermore, an overdose may occur if the target $C_{t}$ value is not adjusted according to the increase in the $\mathrm{C}_{\mathrm{p}}$ value in order to maintain the AUC value.

Therefore, it should be noted that during the administration of GRC, changes such as those described here may occur in the early period after transplantation. Additionally, in such patients, it may be necessary to use PRG in the early period after transplantation and switch to GRC after the condition stabilizes. However, as the number
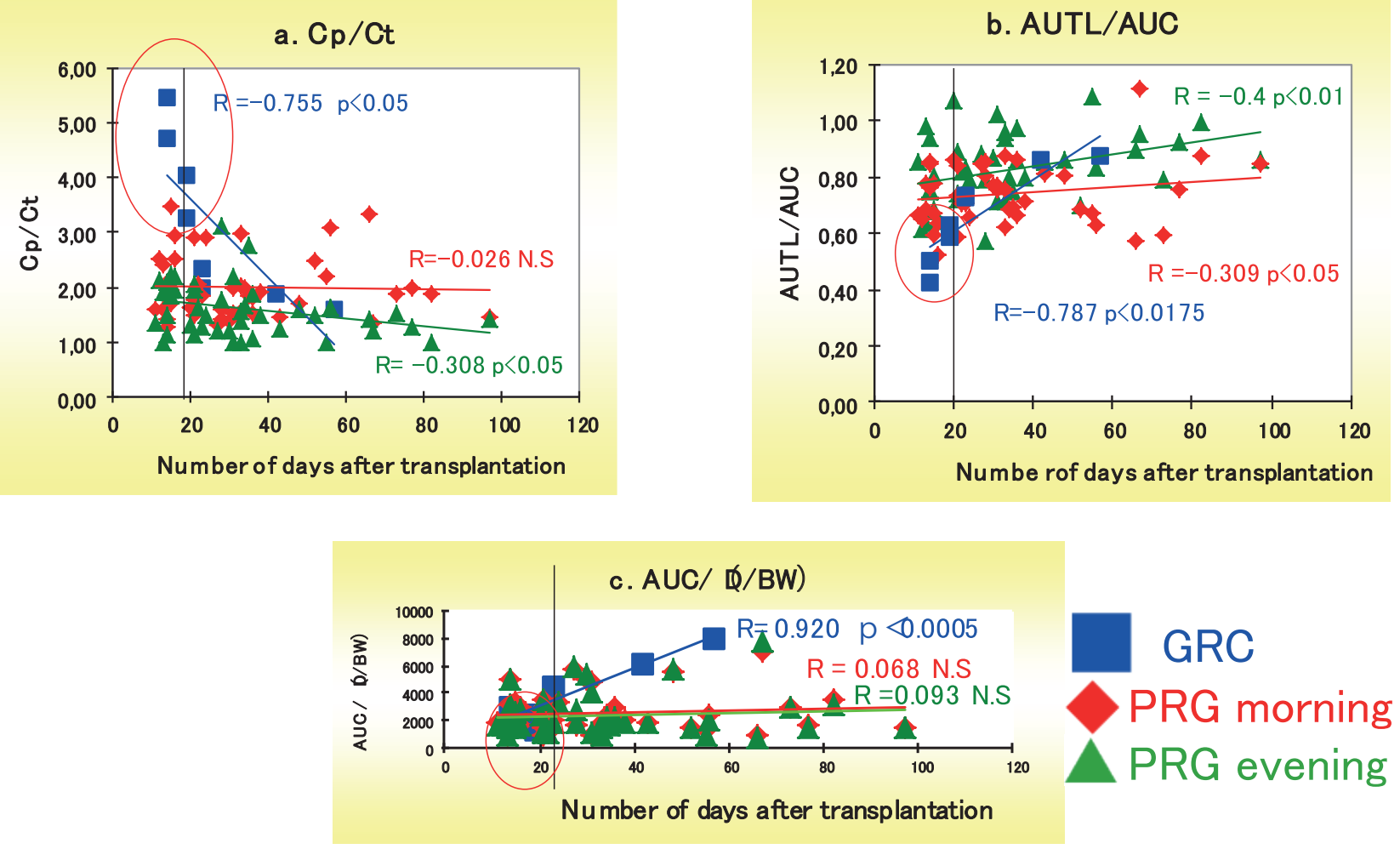

Figure 1: Correlation among pharmacokinetics parameters and number of days after transplantation. 

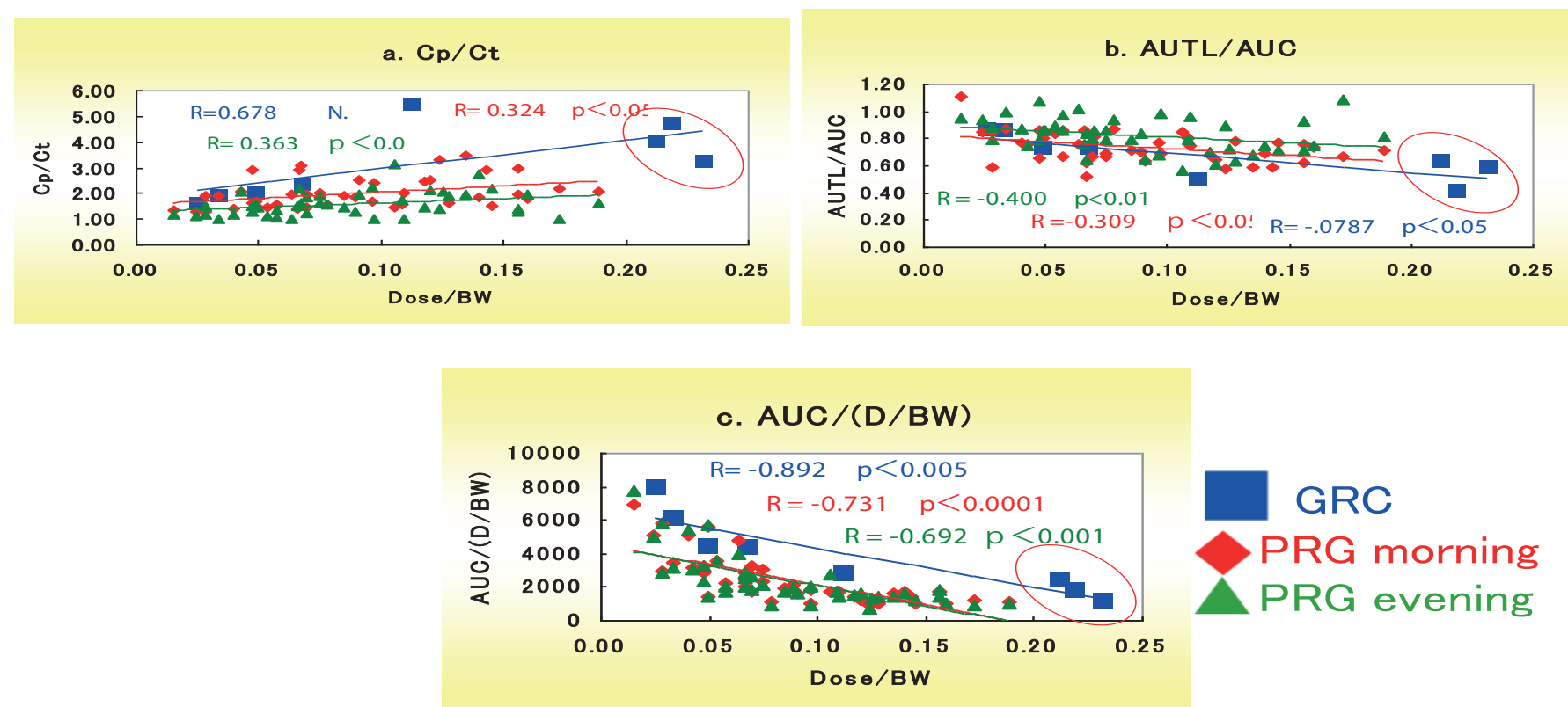

GRC PRG morning PRG evening

Figure 2: Correlation among pharmacokinetics parameters and dose.
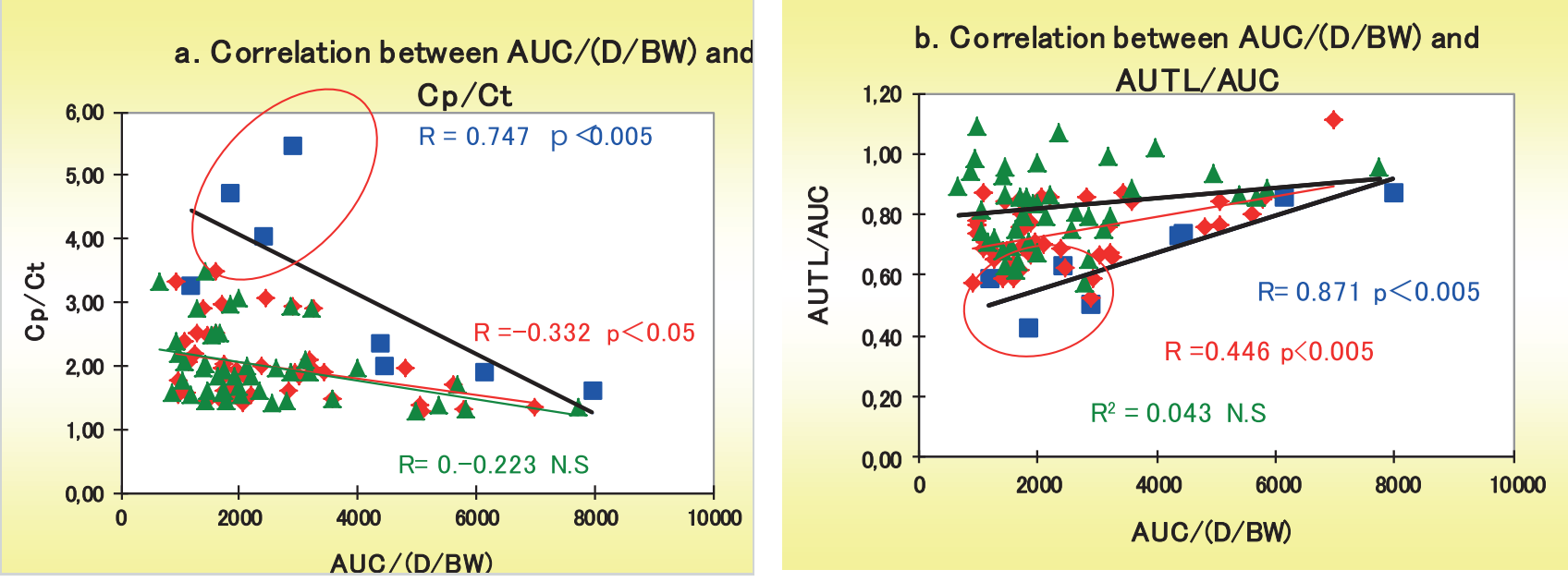

Figure 3: Correlation among pharmacokinetics parameters and bioavailability. 
Citation: Nakamura Y, Takeuchi H, Iwamoto H, Toraishi T, Konno O, et al. (2016) Factorial Analysis on Individual Variability of Tacrolimus ExtendedRelease Formulation Pharmacokinetics in the Early Period after Renal Transplantation-Factors for AUTL/AUC Decrease. J Kidney 2: 112. doi:10.4172/2472-1220.1000112

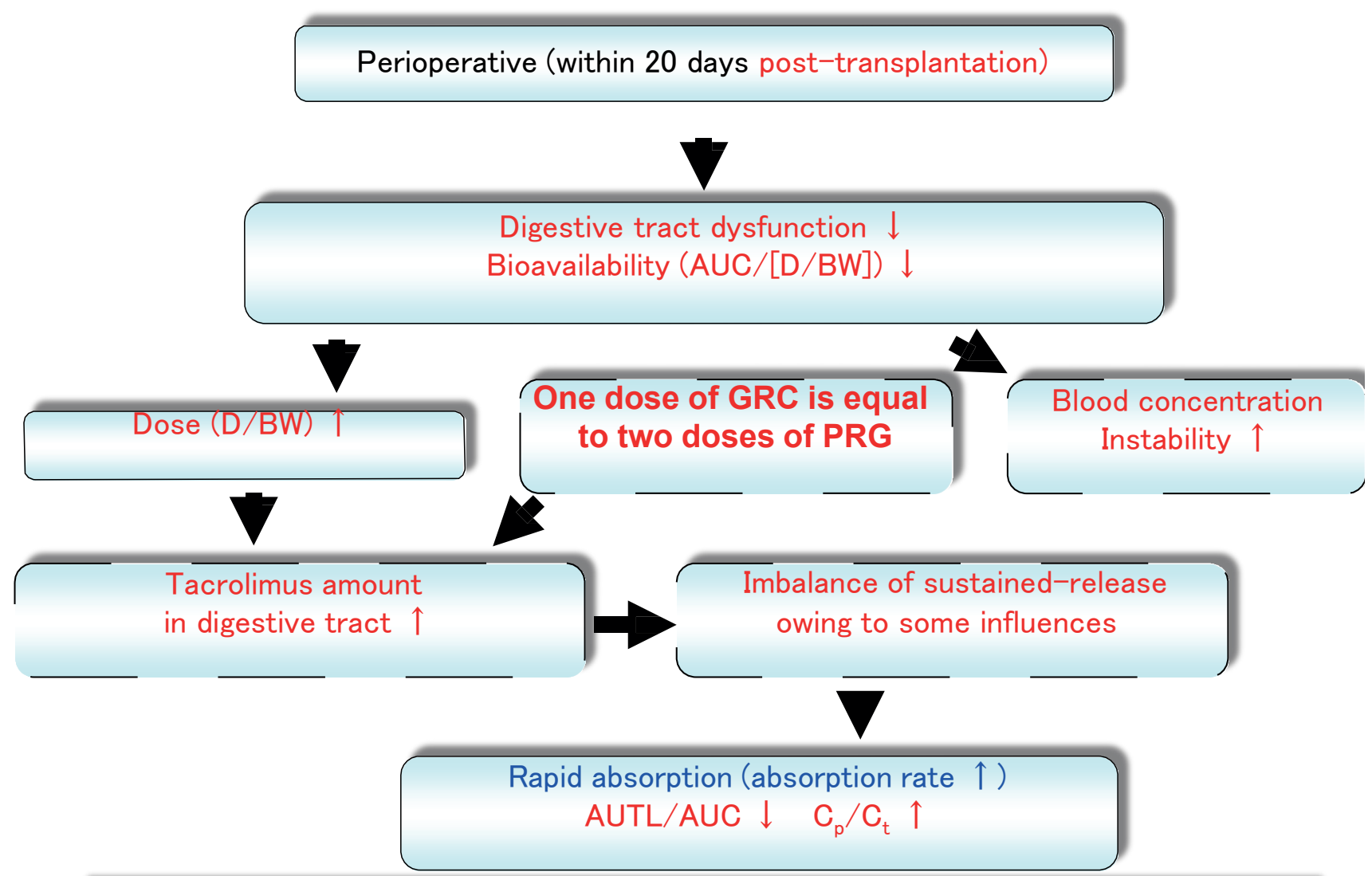
- Blood concentration adjustment becomes difficult
- Increased risk of side effects
- When trying to reach a similar AUC, there is a possibility of overdose
if a low target $C_{t}$ is not set

Figure 4: Estimation of the mechanism of reduced AUTL/AUC and increased $C_{p} / C_{t}$.

of GRC-treated patients included here was low, future studies need to examine numbers of GRC-treated patients.

\section{References}

1. Silva HT Jr, Yang HC, Abouljoud M, Kuo PC, Wisemandle K, et al. (2007) One-year results with extended-release tacrolimus/MMF, tacrolimus/MMF and cyclosporine/MMF in de novo kidney transplant recipients. Am J Transplant 7: 595-608.

2. Crespo M, Mir M, Marin M, Hurtado S, Estadella C, et al. (2009) De novo kidney transplant recipients need higher doses of Advagraf compared with Prograf to get therapeutic levels. Transplant Proc 41: 2115-2117.

3. Krämer BK, Charpentier B, Bäckman L, Silva HT Jr, Mondragon-Ramirez G, et al. (2010) Tacrolimus once daily (ADVAGRAF) versus twice daily (PROGRAF) in de novo renal transplantation: a randomized phase III study. Am J Transplant 10: $2632-2643$

4. Kitada H, Okabe Y, Nishiki T, Miura Y, Kurihara K, et al. (2012) One-year followup of treatment with once-daily tacrolimus in de novo renal transplant. Exp Clin Transplant 10: 561-567.

5. Min SI, Ha J, Kang HG, Ahn S, Park T, et al. (2013) Conversion of twice-daily tacrolimus to once-daily tacrolimus formulation in stable pediatric kidney transplant recipients: pharmacokinetics and efficacy. Am J Transplant 13: 2191-2197.

6. Shuker N, Cadogan M, van Gelder T, Roodnat JI, Kho MM, et al. (2015)
Conversion from twice-daily to once-daily tacrolimus does not reduce intrapatient variability in tacrolimus exposure. Ther Drug Monit 37: 262-269.

7. Gallego-Valcarce E, Ortega-Cerrato A, Llamas-Fuentes F, Martinez-Fernandez G, Perez-Martinez J, et al. (2009) Conversion to tacrolimus extended-release formulation: short-term clinical results. Transplant Proc 41: 2326-2327.

8. Hougardy JM, Broeders N, Kianda M, Massart A, Madhoun P, et al. (2011) Conversion from Prograf to Advagraf among kidney transplant recipients results in sustained decrease in tacrolimus exposure. Transplantation 91: 566-569.

9. Nakamura Y, Hama K, Katayama H, Soga A, Toraishi T, et al. (2012) Safety and efficacy of conversion from twice-daily tacrolimus (prograf) to once-daily prolonged-release tacrolimus (graceptor) in stable kidney transplant recipients. Transplant Proc 44: 124-127.

10. Takeuchi H, Matsuno N, Senuma K, Hirano T, Yokoyama T, et al. (2008) Evidence of different pharmacokinetics including relationship among AUC, peak, and trough levels between cyclosporine and tacrolimus in renal transplant recipients using new pharmacokinetic parameter-Why cyclosporine is monitored by C2 level and tacrolimus by trough Level. Bio Pharm Bull 31: 90-94. 